\title{
Ionospheric electron density observed by FORMOSAT-3/COSMIC over the European region and validated by ionosonde data
}

\author{
Andrzej Krankowski • Irina Zakharenkova • \\ Anna Krypiak-Gregorczyk · Irk I. Shagimuratov • \\ Pawel Wielgosz
}

Received: 18 June 2010 / Accepted: 4 May 2011 / Published online: 18 May 2011

(C) The Author(s) 2011. This article is published with open access at Springerlink.com

\begin{abstract}
This research is motivated by the recent IGS Ionosphere Working Group recommendation issued at the IGS 2010 Workshop held in Newcastle, UK. This recommendation encourages studies on the evaluation of the application of COSMIC radio occultation profiles for additional IGS global ionosphere map (GIM) validation. This is because the reliability of GIMs is crucial to many geodetic applications. On the other hand, radio occultation using GPS signals has been proven to be a promising technique to retrieve accurate profiles of the ionospheric electron density with high vertical resolution on a global scale. However, systematic validation work is still needed before using this powerful technique for sounding the ionosphere on a routine basis. In this paper, we analyze the properties of the ionospheric electron density profiling retrieved from COSMIC radio occultation measurements. A comparison of radio occultation data with groundbased measurements indicates that COSMIC profiles are usually in good agreement with ionosonde profiles, both in the F2 layer peak electron density and the bottom side of the profiles. For this comparison, ionograms recorded by European ionospheric stations (DIAS network) in 2008 were used.
\end{abstract}

Keywords FORMOSAT-3/COSMIC · GPS - Ionosonde · Ionosphere $\cdot$ Radio occultation

A. Krankowski (凶) · I. Zakharenkova · A. Krypiak-Gregorczyk · P. Wielgosz

Geodynamics Research Laboratory, University of Warmia and

Mazury in Olsztyn, Olsztyn, Poland

e-mail: kand@uwm.edu.pl

I. Zakharenkova $\cdot$ I. I. Shagimuratov

West Department of IZMIRAN, Kaliningrad, Russia

\section{Introduction}

Various radio occultation (RO) space missions have proven successful in addressing a broad range of scientific questions on climate change analysis, validating climate simulations, ionospheric research and space weather forecasting, calibrating other observing systems (e.g. radiosonde and other satellite observations), ionosphere studies (layered structures of the $\mathrm{F}$ and $\mathrm{E}$ layers and global distribution of the sporadic Es layers) and geodesy (e.g. Kirchengast et al. 2004; Liou et al. 2010).

The RO technique using GPS signals was first realized with the MicroLab 1 satellite, also known as OrbView 1, launched on April 3, 1995. This mission payload had an atmospheric monitoring instrument (GPS/MET). Besides the main goal of weather monitoring, GPS/MET sensor has also been able to sound the ionosphere from its orbit altitude to the Earth surface and retrieve one-dimensional profiles of the ionospheric electron density from measurements of ray-path bending angle or total electron content (TEC) (Hajj and Romans 1998; Schreiner et al. 1999; Hocke and Igarashi 2002). In subsequent years, several programs with GPS RO experiments have been carried out, such as SAC-C (e.g. Colomb et al. 2004), IOX (e.g. Straus et al. 2003), CHAMP (e.g. Jakowski et al. 2002; Jakowski 2005; Wickert et al. 2009), GRACE (e.g. Beyerle et al. 2005). These satellites performing RO experiments are mainly solo-satellite missions which are not dedicated to monitor space weather rapid changes on a global scale.

The current LEO mission-FORMOSAT-3/COSMIC (Taiwan's Formosa Satellite Mission \#3/Constellation Observing System for Meteorology, Ionosphere and Climate), throughout this paper denoted as COSMIC, is a joint scientific mission of Taiwan and the U.S. and was launched on April 15, 2006. The mission placed six micro-satellites into 
six different orbits at $700-800 \mathrm{~km}$ above the Earth's surface. The orbit inclination is $72^{\circ}$. Each microsatellite has a GPS Occultation Experiment (GOX) payload to operate the ionospheric RO measurements. Depending on the state of the constellation, COSMIC has been producing 1,500-2,500 good soundings of the ionosphere and atmosphere per day, uniformly distributed around the globe. This number of RO is much higher than even before. The total number of ionospheric occultations for 2006-2009 is more than 2,000,000 (more than 50,000 profiles per month). Previous missions were able to produce only 4,000-6,000 RO profiles per month (only several hundred per day). Therefore, COSMIC data can make a positive impact on a global ionosphere study, providing essential information about the height electron density distribution; particularly over regions that are not accessible with ground-based measuring instruments such as ionosondes and GPS dual-frequency receivers. The main purpose of this paper is to examine the accuracy of retrieved COSMIC RO profiles over the European region by comparing them with vertical ionosonde data. This research is motivated by the recent IGS Ionosphere Working Group recommendation issued at the IGS 2010 Workshop held in Newcastle, UK. This recommendation encourages studies on the evaluation of the application of COSMIC RO profiles for additional IGS global ionosphere map (GIM) validation.

\section{Data analysis}

\subsection{COSMIC data}

Since May 2006, the retrieved electron density (Ne) profiles have been available from the Taiwan Analysis Center for COSMIC (TACC, http://tacc.cwb.gov.tw/en/) and the COSMIC Data Analysis and Archive Center (CDAAC, http:// www.cosmic.ucar.edu/cdaac/). As was already mentioned, COSMIC can provide over 2,000-2,500 RO measurements per day, and more than $70 \%$ of the RO measurements can be successfully retrieved into Ne profiles, which are one of the most important products for space weather and ionospheric science. Figure 1 illustrates the global distribution of the COSMIC RO points during one day.

In order to invert RO TEC data to one-dimensional $\mathrm{Ne}$ as a function of tangent point altitude (point of closest ray path approach to the Earth), the Abel inversion is one of the most commonly used techniques. Derivation of the ionospheric electron density from RO measurements is described in more detail by Tsai et al. (2001). At CDAAC, the ionospheric profiles are also retrieved by the Abel inversion from TEC along LEO-GPS rays. Detailed description of CDAAC data processing and the Ne profile retrieval method can be found in Kuo et al. (2004) and Syndergaard et al. (2006). The error sources of Ne profiles derived from RO

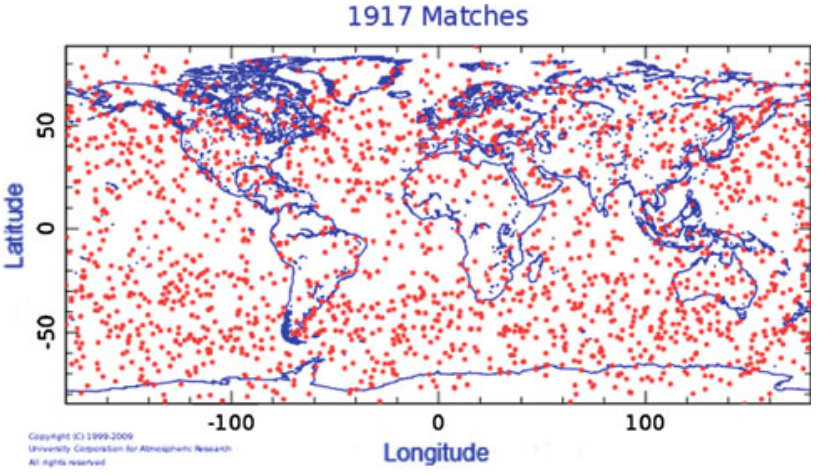

Fig. 1 Example of global distribution of the COSMIC RO points during May 1, 2008 (http://tacc.cwb.gov.tw/cdaac/DBif/cdaac_highlevel. cgi)

measurements mainly include the assumptions made in the inversion method and the measurement errors. The assumptions in the Abel inversion technique include the spherical symmetry of electron density distribution and the straightline propagation of the radio waves in the ionosphere. The measurement errors include the carrier phase errors of GPS signals and the orbital errors. A study of the error sources by Wu et al. (2009) showed that measurement errors are negligible; the approximation of straight-line propagation induces errors at the height of the F1 layer under the solar maximum condition. The main source of inversion error is the spherical symmetry approximation. Yue et al. (2010) compared COSMIC Ne profiles with those obtained from the NeQuick empirical ionosphere electron density model. These simulations demonstrated that the Abel inversion method introduces significant errors in electron densities in the low-latitude region. The spherical symmetry assumption is not satisfied at low latitudes where electron density has strong horizontal gradients. The retrieval errors are relatively small at all altitudes at middle and high latitudes. Several studies have attempted to improve the Abel inversion method (Hernandez-Pajares et al. 2000; Garcia-Fernandez et al. 2003, 2005; Tsai et al. 2009). At present, it is still difficult to quantitatively evaluate the Abel retrieval error globally because there are not enough coincidences between RO and independent observations to provide good temporal and spatial coverage.

For this study, we used second level data provided by CDACC- “ionprf" files containing information about ionospheric electron density profiles. Note that COSMIC sounding points during the day have rather good global distribution. We have selected occultations whose tangent points of signal ray path were within the limits of European region. The path of the tangent point during one occultation event is called the occultation trace. Usually, the total number of the occultation events in the European region is about 35-50 per day. Figure 2 shows an example of a map with occultation points over Europe during one day (May 1, 2008). In 


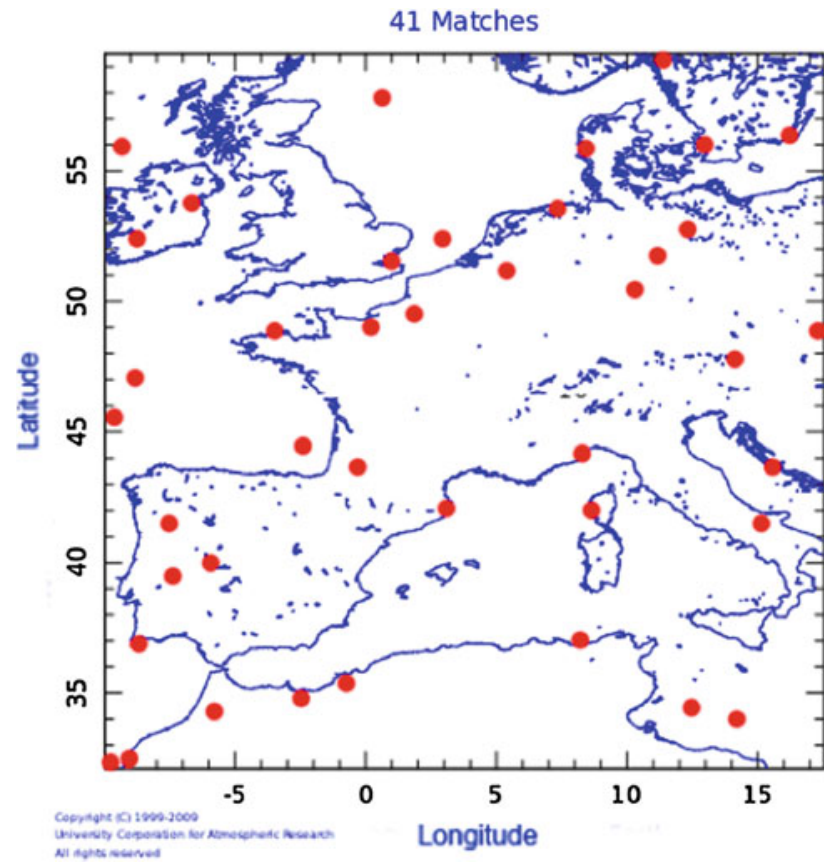

Fig. 2 Map with COSMIC RO points over the European region (http:// tacc.cwb.gov.tw/cdaac/DBif/cdaac_highlevel.cgi)

this study, COSMIC RO data from 2008 were analyzed. It is necessary to note that a small part of the COSMIC electron density profiles are affected by cycle slips in the GPS phase data. In some cases, this results in obviously distorted profiles, whereas in other cases the errors due to cycle slips are more subtle. There is a need to analyze the data quality and to fix or remove bad or questionable data; especially before its application in any automatic routine. For this validation study, we focused on the manual checking and painstaking screening of initial data. The detected bad RO profiles were removed from the analysis.

\subsection{Ionosonde data}

Ionosondes, one of the first radar sounding techniques, provide direct and accurate measurements of the ionospheric plasma density; therefore, ionosondes are typically used as diagnostic tools for calibrating other more complicated observation methods such as incoherent scatter radar, satellite beacon tomography and RO. Ionosondes directly measure electron density at the ionospheric F2 layer peak (NmF2) since $\mathrm{NmF} 2 / \mathrm{m}^{-3}=(1 / 80.6)(\mathrm{foF} 2 / \mathrm{Hz})^{2}$, where foF 2 is the measured critical frequency of the F2 layer. The peak height is obtained from the true height inversion (Reinisch and Huang 2001). In order to validate the reliability of the COSMIC data, we have used the ionograms, foF2 values and electron density profiles provided by the European Digital Upper Atmosphere Server (DIAS). Since May 2005 the DIAS server (http://www.iono.noa.gr/DIAS) has been deliv-
Table 1 Geographical position of the ionosondes (DIAS network)

\begin{tabular}{llc}
\hline Ionospheric station & Latitude $\left(^{\circ}\right)$ & Longitude $\left(^{\circ}\right)$ \\
\hline Athens & 38.0 & 23.5 \\
Chilton & 51.5 & 359.4 \\
El Arenosillo & 37.1 & 353.3 \\
Ebre & 42.4 & 2.6 \\
Juliusruh & 54.6 & 13.4 \\
Pruhonice & 50.0 & 14.6 \\
Rome & 41.9 & 12.5 \\
\hline
\end{tabular}

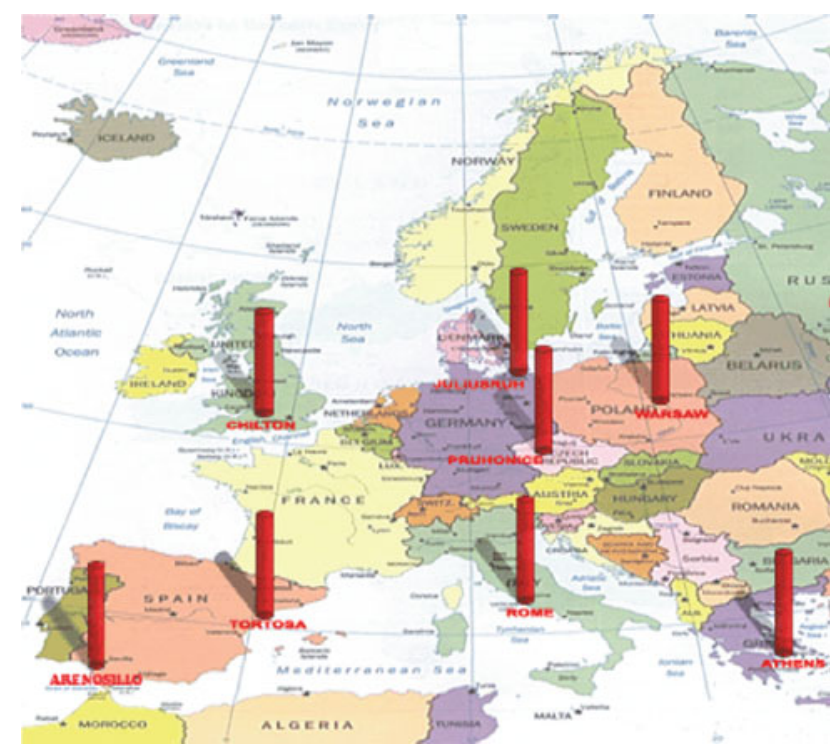

Fig. 3 Geographical map of ionosonde stations (DIAS network)

ering such products as real-time and archive ionograms from all DIAS ionosonde stations, frequency plots and maps of the ionosphere over Europe based on the foF2, M(3000)F2, MUF and electron density parameters (Belehaki et al. 2005). This server collects information from stations located in Rome, Pruhonice, Juliusruh, Athens, Chilton, Ebre and El Arenosillo (Table 1). Figure 3 illustrates the geographical position of the considered ionosondes in European region. At these stations, the ARTIST (Automated Real Time Ionogram Scaler with True height) software for ionogram automatic scaling in real time is used. The ARTIST system is a very skilled algorithm characterized by high percentages of reliable auto-scaled data (Reinisch et al. 2005; McNamara 2006). Real-time ionosonde ionograms are scaled by an auto-scaling program and sent to the server. However, serious autoscaling errors can occur and it is recommended to check the ionosonde dataagainst the ionogram of the same sounding for accuracy. Figure 4 illustrates samples of original ionograms with results of their automatic processing for Juliusruh ionosonde registered at October 11, 2009 for the moments of 
Fig. 4 Examples of two ionograms with automatic trace identification and ionospheric parameters extraction for Juliusruh ionosonde. On the ionograms, ordinary trace (in $r e d$ ), extraordinary trace (in green) and automatically reconstructed ordinary trace (in black) are drawn. Sounding frequency is indicated at the abscissa and virtual reflection height - at the ordinate. The numerical information derived by auto-scaling program is shown in the bottom of the diagram (http://dias.space.noa. gr:8080/LatestDias2/loginPage. jsp)
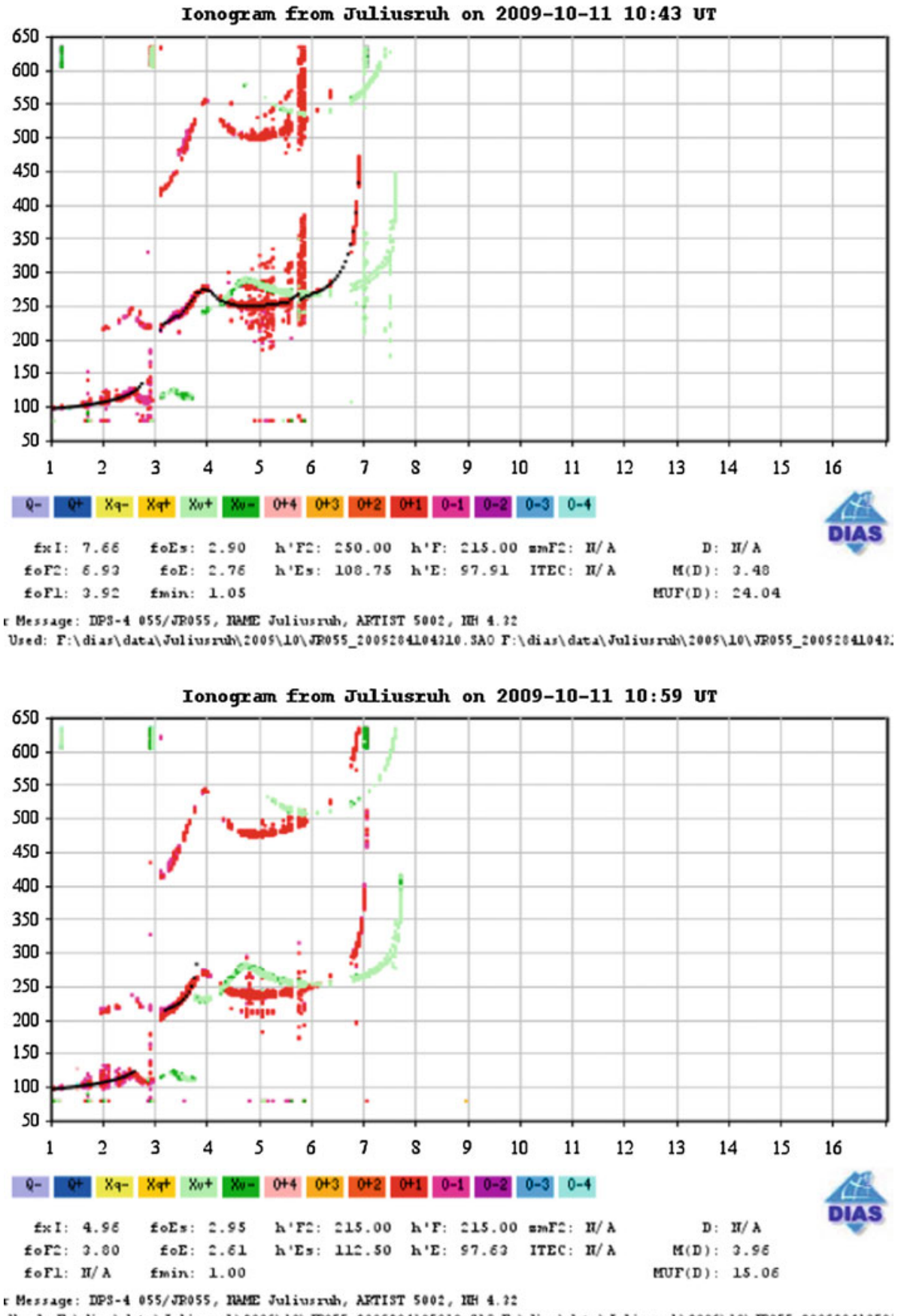

10.43 UT and 10.59 UT. The red curve represents the ordinary echo trace and the green curve represents the extraordinary trace. Automatically reconstructed ordinary trace is indicated by black dotted line. In the first case, it can be seen that the automatically scaled ordinary trace corresponds to the real representation of the ordinary trace at the actual ionogram, the foF2 value is determined as 6.93 MHz. In the second case, the automatically scaled ordinary trace is incomplete and does not correspond to the actual ordinary trace (red curve). Automatic program defines a critical fre- quency of foF2 as $3.80 \mathrm{MHz}$, but this value is corresponding to the critical frequency of F1 layer, not F2, whereas the valid value of foF2 is equal to $7.05 \mathrm{MHz}$. This error results in a distortion of the electron density profile inverted from scaled ordinary trace. DIAS database provides Ne profiles related to the considered ionograms (Fig. 5). The topside of the ionosphere is constructed by fitting a model to the peak Ne value. Visual comparison of "true" and "false" profiles presents a significant difference in the profile shape, peak electron density $(\mathrm{NmF} 2)$ and F2 layer height (hmF2) values. The second 
Electron Density over Juliusruh 2009/0/1 @ 10:45 UT

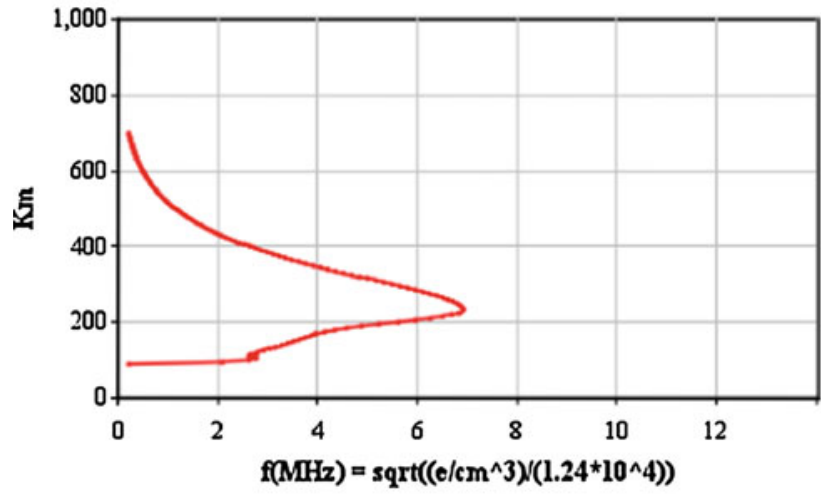

Electron Density over Juliusruh 2009/0/1 @ 11:00 UT

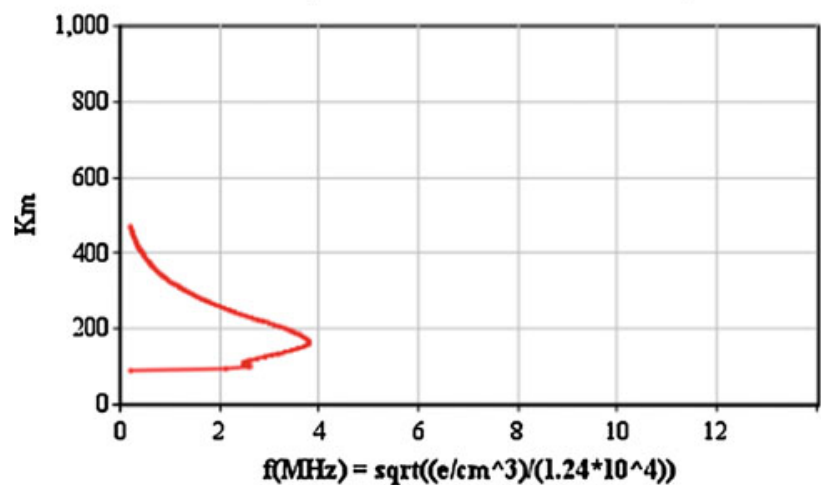

Fig. 5 Electron density profiles corresponding to the measurements in Fig. 4

profile in Fig. 5 is "false" and must be corrected or excluded from the analysis. This example illustrates the necessity of manual scaling for data quality. To avoid evident risks related with using auto-scaled data with ionosonde-related errors and uncertainties, we carried out manual verification of all autoscaled values involved (foF2, traces, electron density profiles) with ionograms from the DIAS database.

\subsection{Comparative analysis}

In this study, COSMIC RO data validation was carried out by comparison with ionosonde measurements. The applied algorithm consists of several steps. First, the COSMIC "ionprf" files are processed and RO points located in European region are selected; each selected profile is checked for a data quality. Next, a visualization of RO ray path of tangent points and the choice of the nearest ionosonde station is represented graphically. This is followed by processing, interpretation and preparation of the ionosonde data, including the ionogram control at the DIAS database. Finally, graphs with RO and ionosonde Ne profiles are created, and it is possible to realize procedures to obtain and estimate com- parative characteristics. However, it is necessary to note that RO-retrieved electron density profiles should not be interpreted as actual vertical profiles. The geographical location of the tangent points' path at the top and at the bottom of a profile may differ by several hundred kilometers. In this way, the spatial smearing of data takes place and the RO technique represents an image of the vertical and horizontal ionospheric structure. That is why a comparison with ground-based data has a rather relative character, but validation of RO measurements can be done only with independent instruments, such as ground-based ionosondes which provide direct measurements of electron density. This validation constitutes a necessary test of RO-derived $\mathrm{Ne}$ profiles. The ionosonde and RO measurements are not identical in origin and there are some discrepancies caused by different techniques and geographical location. However, our approach is based on the research of the ionospheric spatial correlation (e.g. Klobuchar and Kunches 2000; Yue et al. 2007). It is well-known that the correlation distance of the ionosphere depends on direction and can be regarded as anisotropic. The correlation distance of the ionosphere (correlation coefficient $r>0.70$ ) is approximately 2,500-3,000 km in the east-west direction and 1,600$1,800 \mathrm{~km}$ in the north-south direction. At the mid latitudes, for quiet geomagnetic conditions, a correlation coefficient $r>0.85-0.90$ corresponds to the correlation distance of $1,000-1,500 \mathrm{~km}$. Therefore, it is reasonable to select RO points within this correlation distance from the ionosonde position.

\section{Results and discussion}

\subsection{Comparison with European ionosondes data (case-study)}

Since the location of RO profiles depends only on the LEO satellite path and occultation traces, it is not characterized by day-by-day reiteration in the same form over a single point. Therefore, special attention was paid to the geographical position of the occultation traces in the European region and their location relative to the location of the ionospheric stations. For this purpose, graphs with visualization of the occultation traces in geographic coordinates were provided. A rather rare and interesting event was observed when two or three occultation traces were registered in the vicinity of a single ionosonde at the same time. For example, Fig. 6a illustrates the case with two simultaneous occultation events near the Pruhonice ionospheric station registered at 14:14 UT on March 5, 2008. One can observe some differences in NmF2 values for these two cases between COSMIC and ionosonde profiles drawn by solid and dotted lines, respectively. Such observations indicate the insufficiency of the plane visualization of the occultation traces for comprehensive analysis. 

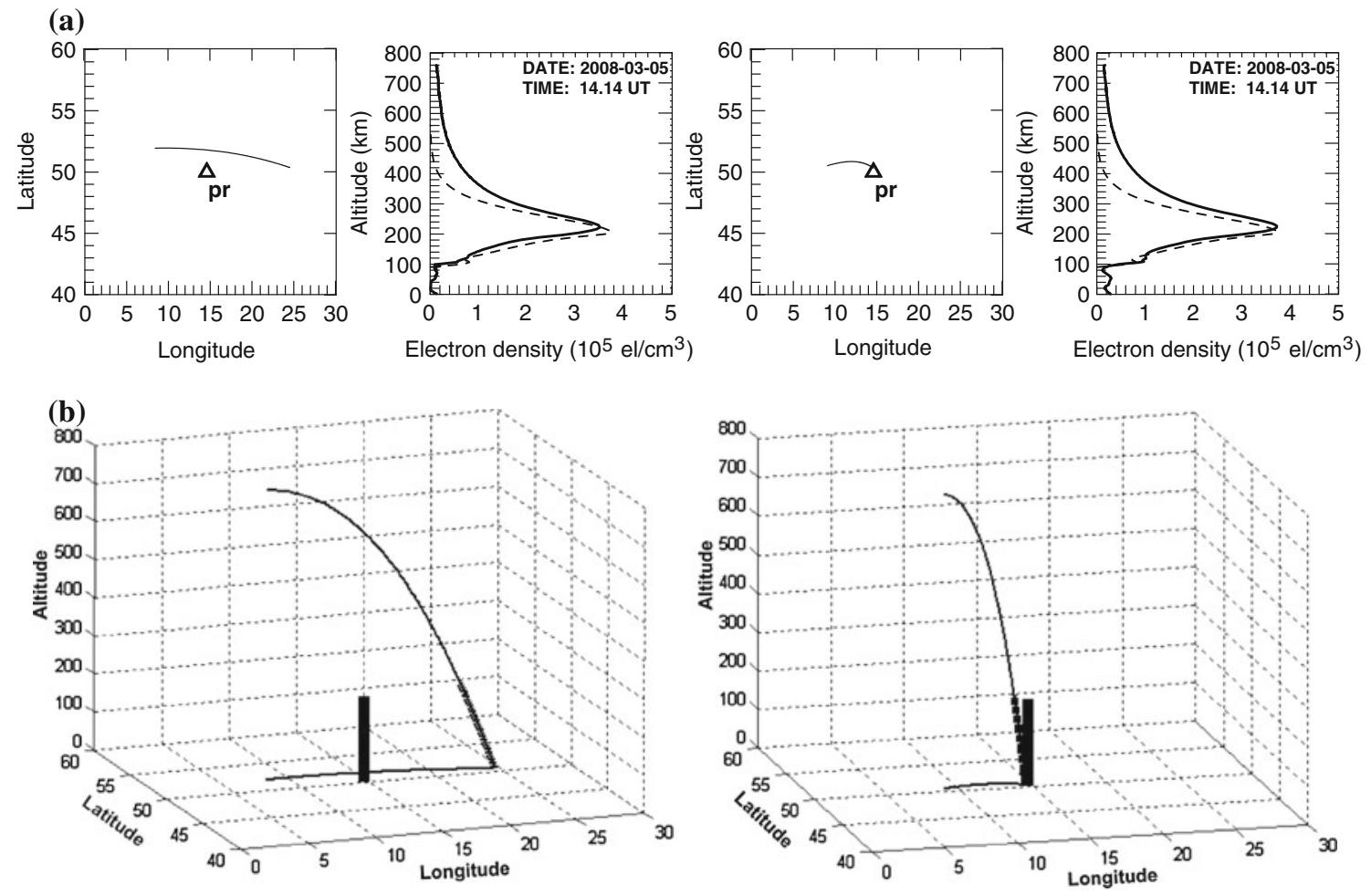

Fig. 6 Example of two simultaneous occultation events. Position of occultation traces relative to the European ionosonde network and comparison of COSMIC (solid line) and Pruhonice ionosonde (dotted line)

electron density profiles are presented. The triangle represents the position of Pruhonice ionosonde. In the bottom panel the 3D geometry of occultation trace is presented

In most cases, such divergences between profiles can be explained by three-dimensional geometry of the occultation ray path. In fact, as the sounders provide no direct information on the profile above the maximum electron density, we can compare only that part of the RO trace which corresponds to heights up to the F2 layer peak and it is important how far this part of trace is located from the ionospheric station. Figure $6 \mathrm{~b}$ shows $3 \mathrm{D}$-visualization of the occultation traces (curve indicated the motion of the tangent point) for the considered case of simultaneous events. One can see a vertical column illustrating the part of the ionosphere measured by Pruhonice ionosonde sounding (up to the F2 layer peak for the given time) and occultation traces changing with altitude and its projection into latitude-longitude coordinates. It is evident that in the case when the bottom side of occultation trace is located close the ionosonde's position, the agreement between profiles is better. It is necessary to note that in the case of rather long occultation traces, a spatial smearing of data takes place. Due to the presence of latitudinal gradients in the ionosphere, the COSMIC profile represents spatial averaged information about electron density and can differ noticeably from the ionosonde data.

Figure 7 presents an example of another event-a rather short RO trace is situated among three ionospheric stations.
Therefore, possible differences in the profiles may be estimated depending on the choice of ionosonde. The bottom-side part of the occultation trace is shown by crosses and a 3D-visualization of the occultation trace and the position of the ionosondes are also presented. At the bottom panel there are comparisons of the COSMIC and ionosonde electron density profiles. The RO trace is located close to Pruhonice ionosonde, but it has a southward direction-the heights are the same but the ionosonde peak density is smaller than the COSMIC profile. The best agreement in both the height and value of the F2 layer peak can be observed for Rome ionosonde, but it is located far to the south from the bottom part of the RO trace, where the electron concentration is higher and one can see that the ionosonde peak density is greater than the COSMIC profile. As for Ebre ionosonde, there are differences both in the height and peak electron density as this ionosonde is located rather far from the RO trace.

In this way, a comparison of COSMIC and ionosonde electron density profiles for the series of 15 days in March 2008 was carried out. COSMIC occultations occurring between 12-15 UT and RO traces located close to Pruhonice ionospheric station were selected. First, we estimated the agreement of the bottom parts of profiles and position of $\mathrm{F} 2$ 

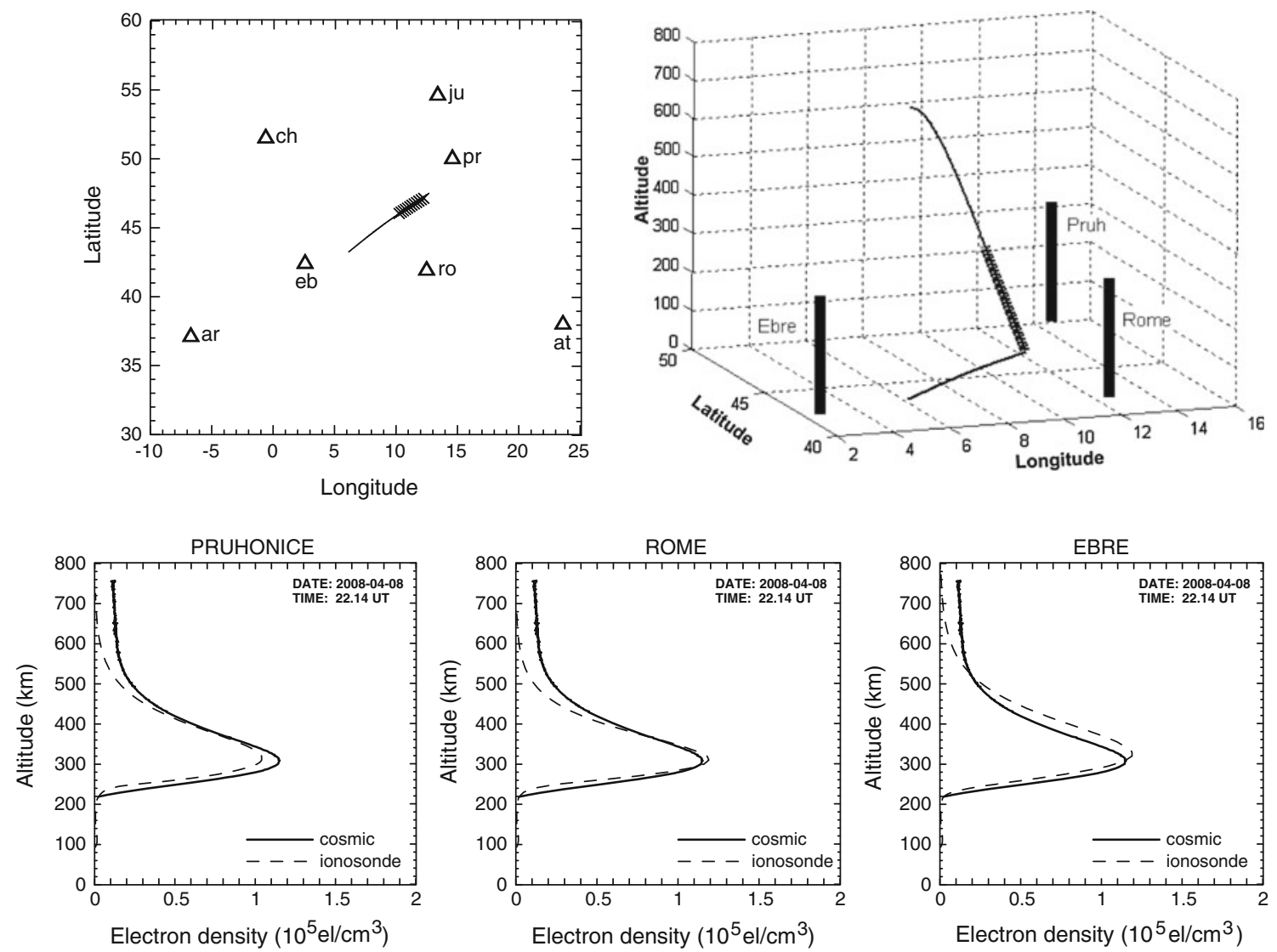

Fig. 7 Comparison of Ne profiles (COSMIC with three nearest ionosondes). In the top panel the 2D and 3D geometry of occultation trace is presented

ionospheric layer maximum. Figure 8 illustrates the comparison of COSMIC and ionosonde profiles, as well as the geographic position of RO traces relative to the Pruhonice ionosonde. This figure provides the general information on day-by day coincidence/disagreement between independent measurements. Also, the differences $\mathrm{NmF} 2$ and $\mathrm{hmF} 2$ of the maximum value and height of the F2 layer peak were analyzed for every figure. Numerical results of this comparison are presented in Table 2. The fourth column $(D)$ contains the distance between a ionosonde and a point of RO trace which corresponds to the F2 layer peak (i.e. the distance between two points where $\mathrm{NmF} 2$ is measured by ionosonde and $\mathrm{RO}$ ). For the given series, the difference in $\mathrm{NmF} 2$ was within the limits of $10 \%$, except the case of March 12, where one of the most significant differences between profiles was observed and the distance between points was the maximal one (972 $\mathrm{km})$. For events corresponding to the days of March 4, 6, 16 and 18 , the value of $\Delta \mathrm{NmF} 2$ was less than $4 \%$, while the distance between points of measurements was several hundred $\mathrm{km}$. It can be explained by the fact that these points were located at different longitudes, but practically at the same latitude and, in this direction (east-west), the ionosphere correlation distance is high. We did not observe any unique dependence between the differences in $\mathrm{hmF} 2$ values and point distances.

In the next analyses, the nearest GPS station to Pruhonice ionosonde (distance $\sim 56 \mathrm{~km}$ )—GOPE (Ondrejov, Czech Republic) with geographic coordinates of $49.9 \mathrm{~N}, 14.8 \mathrm{E}$ was selected. GPS measurements for the GOPE station were processed for the selected time and the TEC values were calculated. In order to compare GPS TEC with RO and ionosonde data, the electron densities from these profiles were integrated. In addition, data integration up to the height of $\mathrm{NmF} 2$ was carried out. Figure 9 demonstrates the results of these calculations. Each bar graph illustrates GPS TEC, COSMIC and Ionosonde IEC (ionospheric electron content). The crosshatched histogram bar indicates the electron content up to the height of the peak electron density, i.e., bottom-side parts of IEC. It is clearly seen that, in general, the bottomside parts of COSMIC and ionosonde data are in rather good agreement while the topside varies greatly. This is evidence of differences in the topside part of these profiles. Thus, for practically all the analyzed cases, the observed values of the electron density in the topside part of the ionosonde profiles were lower in comparison with RO profiles. While the topside ionosonde profile was obtained by fitting a model to the 

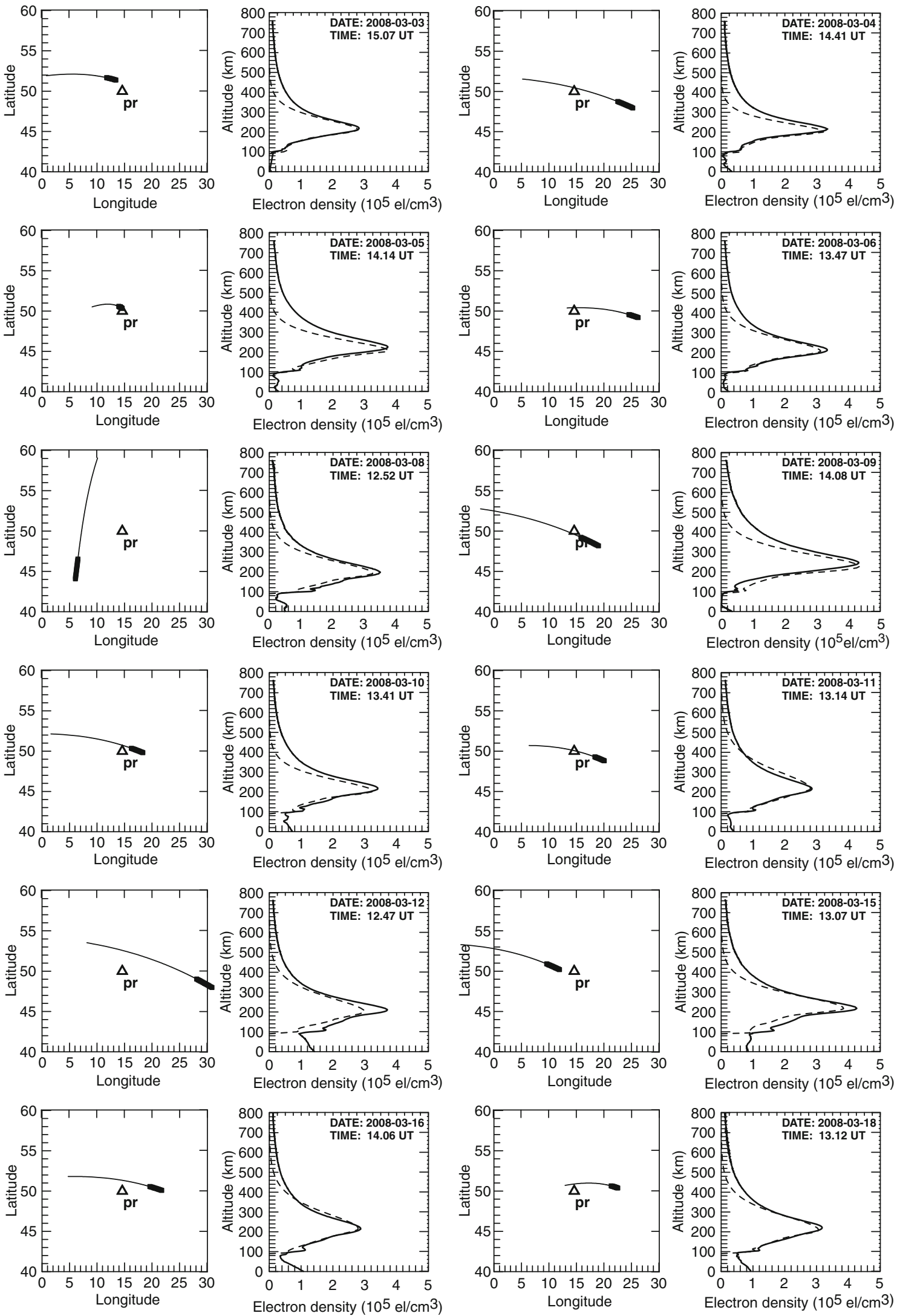

Fig. 8 Comparison of electron density profiles (COSMIC vs. ionosonde) for March 3-18, 2008 
Table 2 Estimates of the difference of $\mathrm{NmF} 2$ and hmF2 between RO and Pruhonice ionosonde during daytime for 3-18 March 2008

\begin{tabular}{|c|c|c|c|c|c|c|c|}
\hline Event & $\Delta \mathrm{NmF} 2(\%)$ & $\Delta \mathrm{hmF} 2(\mathrm{~km})$ & $D(\mathrm{~km})$ & Event & $\Delta \mathrm{NmF} 2(\%)$ & $\Delta \mathrm{hmF} 2(\mathrm{~km})$ & $D(\mathrm{~km})$ \\
\hline $03.0315 .07 \mathrm{UT}$ & 1.2 & 7.8 & 278 & $10.0313 .41 \mathrm{UT}$ & 4.9 & 12 & 115 \\
\hline $04.0314 .41 \mathrm{UT}$ & 4.0 & 14.3 & 290 & $11.0313 .14 \mathrm{UT}$ & 1.7 & 2.4 & 271 \\
\hline $05.0314 .14 \mathrm{UT}$ & -0.4 & 20.0 & 82 & $12.0312 .47 \mathrm{UT}$ & 23.7 & 11.0 & 972 \\
\hline $06.0313 .47 \mathrm{UT}$ & 6.6 & 6.5 & 713 & $15.0313 .07 \mathrm{UT}$ & 10.7 & 0.6 & 374 \\
\hline $08.0312 .52 \mathrm{UT}$ & 7.4 & 5.9 & 711 & $16.0314 .06 \mathrm{UT}$ & 2.9 & -0.6 & 356 \\
\hline $09.0314 .08 \mathrm{UT}$ & -0.6 & 20.8 & 113 & $18.0313 .12 \mathrm{UT}$ & 3.8 & 12.0 & 480 \\
\hline
\end{tabular}
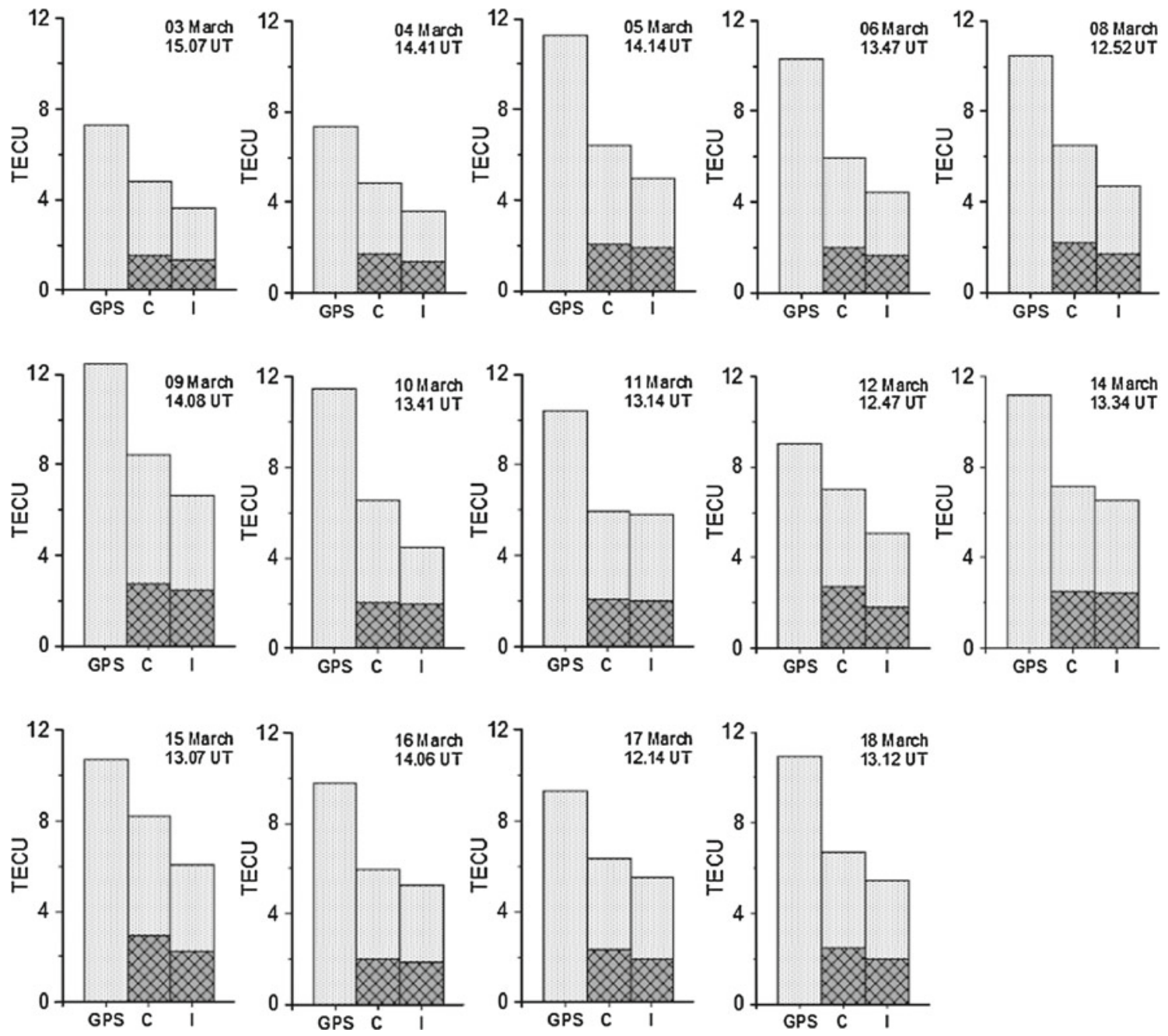

Fig. 9 Comparison of GPS TEC measurements (over GOPE station) with IEC calculated from COSMIC and ionosonde measurements. The first bar (GPS) presents GPS TEC, second bar (C)—COSMIC IEC,

peak electron density value, COSMIC provides experimental data and can make an important contribution to the investigation of the topside part of the ionosphere. It is also necessary to note that GPS TEC values are greater than COSMIC and ionosonde data as GPS TEC contains IEC and PEC (plasmaspheric electron content). This procedure can be useful to estimate the impact of PEC into TEC. third bar (I) - IEC derived from ionosonde profile. The crosshatched histogram bar indicates the bottom-side parts of IEC

In order to obtain statistical results of the comparison between COSMIC and ionosonde profiles, the profiles corresponding to different seasons of year 2008: January, April, July and October were analyzed. For this purpose, occultation traces located in the vicinity of Pruhonice and Juliusruh ionosondes were selected. The data of RO and ionosondes were also manually checked before comparison. The bad 

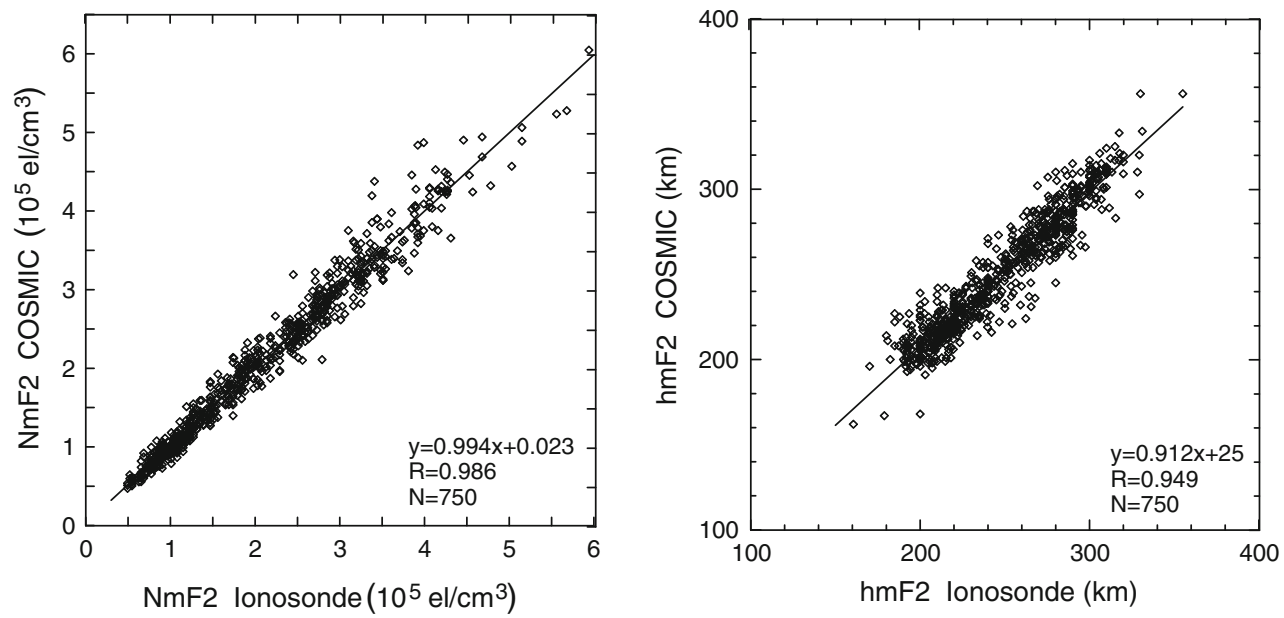

Fig. 10 The scatter plots of COSMIC NmF2 and hmF2 values against the corresponding ionosonde ones. The solid line corresponds to the best fit line

RO profiles affected by cycle-slips were removed and ionosonde Ne profiles were involved only in the case of correctly scaling ionograms. After this screening and selection, the relative differences between COSMIC RO and ionosonde $\mathrm{NmF} 2$ values were calculated with formula (1). Differences of $\mathrm{NmF} 2$ values $(\triangle \mathrm{NmF} 2)$ are presented in percentages in order to make this comparison easier, as ionosphere structure and peak electron densities vary greatly with time (seasonal and diurnal effects). Differences of hmF2 values ( $\Delta \mathrm{hmF} 2)$ are presented in absolute values $(\mathrm{km})$ as these values are usually more informative in the investigations of the ionospheric layers. The total number of the analyzed profiles amounts to 750. To summarize the agreement between COSMIC and ionosonde measurements, Fig. 10 shows the scatter plots of COSMIC NmF2 and hmF2 values against the corresponding ionosonde values. The solid line drawn in the figure corresponds to the best fit line. The scatter plot shows a high degree of correlation between these two independent estimates of $\mathrm{NmF} 2$. The results have a high linear correlation coefficient of 0.986 and a fitting line with a slope of 0.994 and a bias of $0.023 \times 10^{5} \mathrm{el} / \mathrm{cm}^{3}$. In addition, rather good agreement is visible for the heights of the peak electron density.

$\Delta \mathrm{NmF} 2=\frac{\mathrm{NmF} 2_{\mathrm{RO}}-\mathrm{NmF} 2_{\mathrm{I}}}{\mathrm{NmF} 2_{\mathrm{I}}} \cdot 100 \%$

where $\mathrm{NmF} 2_{\mathrm{RO}}-\mathrm{NmF} 2$ derived from $\mathrm{RO}$, and $\mathrm{NmF} 2_{\mathrm{I}}-$ $\mathrm{NmF} 2$ derived from ionosonde observations.

Figure 11 presents histograms with the values of the differences between COSMIC and the ionosonde measurements. It is possible to estimate the dispersion of these values and to calculate the average values. The left graph shows differential $\triangle \mathrm{NmF} 2$ values in percentages and the right one$\Delta \mathrm{hmF} 2$ in $\mathrm{km}$. The $\mathrm{NmF} 2$ differences are characterized by distribution with a mean of $0.72 \%$ and a standard deviation of
$8.42 \%$. In the case of $\mathrm{hmF} 2$ comparison, a mean of $2.80 \mathrm{~km}$ and a standard deviation of $11.46 \mathrm{~km}$ were obtained. The summary in Table 3 displays the results of this comparative analysis.

The data indicate very good agreement between COSMIC $\mathrm{RO}$ and collocated ionosonde observations and demonstrates that the retrieved $\mathrm{NmF} 2$ and $\mathrm{hmF} 2$ are reliable at middle latitudes of European region. It must be noted that qualitative screening of initial data has an influence on the obtained results. Our results are consistent with previous validation results comparing RO retrievals to ionosonde measurements. Comparison of COSMIC Ne profiles with NeQuick-derived profiles revealed good correlation; the standard deviation was $\sim 15 \%$ for $\mathrm{NmF} 2$ and $\sim 2 \%$ for $\mathrm{hmF} 2$ corresponded to global scale analysis (Yue et al. 2010). There are several studies examining and estimating the accuracy of the retrieved COSMIC Ne profiles by comparing them with globally distributed ionosonde data obtained from the National Geophysical Data Center (NGDC-NOAA) SPIDR (The Space Physics Interactive Data Resource) database (http://spidr.ngdc.noaa.gov/ spidr/).

Lei et al. (2007) used data from 31 ionosondes and analyzed 276 coincident measurements made over one month (July 2006). These estimates show a strong correlation between the COSMIC NmF2 and those from ionosondes. The correlation coefficient was 0.85 . Wu et al. (2009) compared the COSMIC-derived $\mathrm{NmF} 2$ values with the measurements of 62 ionosondes; data corresponding to ionosondes were provided by SPIDR. An analysis of globally distributed data showed that the standard deviation of the relative differences in $\mathrm{NmF} 2$ values was $20.7 \%$ with a mean of $-3.2 \%$. For middle latitudes, the standard deviation was $19.6 \%$ with a mean of $-1.3 \%$. The evident advantage of these investigations is the extensive statistics. However, the main vulnerability of these results is the quality of the involved ionosonde 

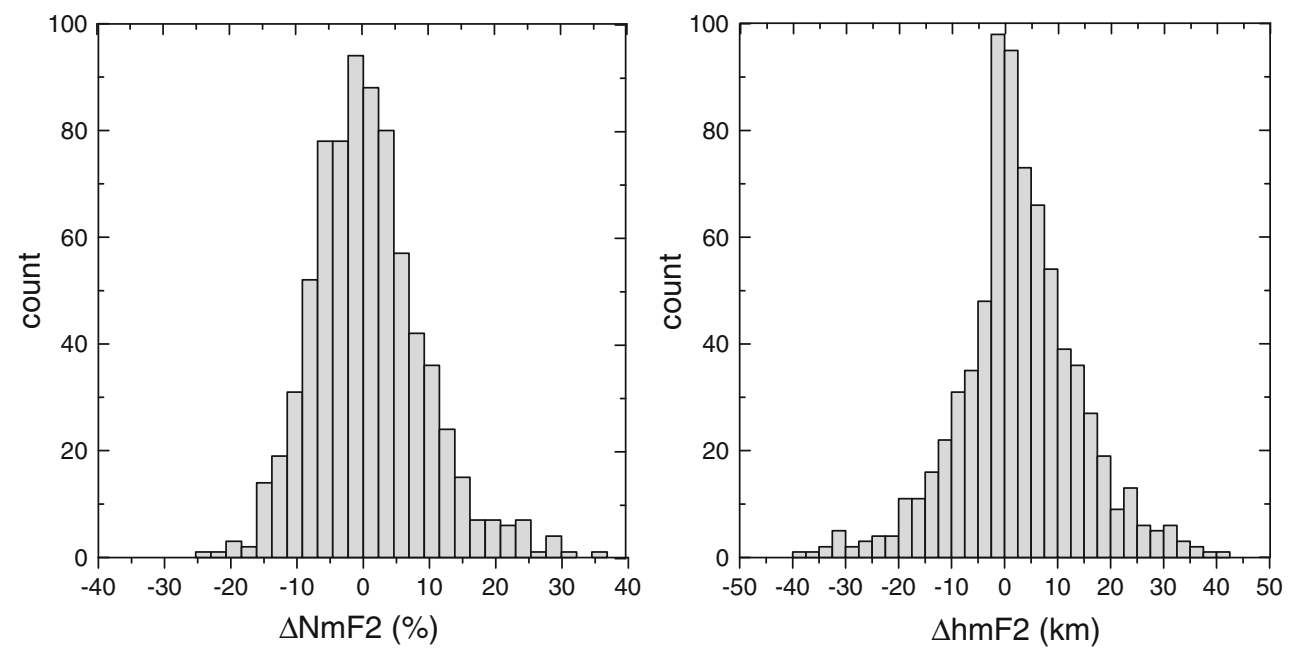

Fig. 11 The histograms of differences between COSMIC and ionosonde measurements in 2008

Table 3 The relative and absolute difference of $\mathrm{NmF} 2$ and $\mathrm{hmF} 2$ between $\mathrm{RO}$ and ionosonde

\begin{tabular}{lllllll}
\hline & \multicolumn{2}{l}{ Standard deviation } & & & Mean & Correlation coefficient \\
\cline { 2 - 3 } & Absolute & Relative (\%) & & Absolute & Relative (\%) & \\
\hline $\mathrm{NmF2}$ & $1.78 \times 10^{4} \mathrm{el} / \mathrm{cm}^{3}$ & 8.42 & & $1.02 \times 10^{3} \mathrm{el} / \mathrm{cm}^{3}$ & 0.72 & 0.986 \\
$\mathrm{hmF} 2$ & $11.46 \mathrm{~km}$ & 4.89 & $2.80 \mathrm{~km}$ & 1.37 & 0.949 \\
\hline
\end{tabular}

data. The SPIDR database provides only automatically scaled data from the ionosonde network and here lays the main weakness of the previous approach. It is impossible determine the exact number of wrongly scaled profiles, which were involved into analysis, as in order to obtain reliable results a manual verification of the corresponding ionograms must be conducted, all ionograms must be checked and rescaled by a specialist scaler, but it is very difficult to realize for large statistical arrays. In this paper, we avoid errors related to auto-scaling processing by manual checking and correction of the ionosonde data, including cases of difficult ionograms scaling. At this point, our estimates are more careful and precise in comparison with the previous investigations. In these circumstances, after initial data screening and manual verification of data, our results of the statistical analysis show higher values of comparative characteristics.

\subsection{Global mapping of COSMIC tomography data}

Another advantage provided by the COSMIC mission is the possibility to study the ionosphere globally and with high vertical resolution. In the past, 3D ionospheric images were limited. Only ionosphere tomographic images constructed by a regional observation chain were able to provide the detailed observation of the structure of the ionosphere. Using dense, worldwide occultation observations carried out by COSMIC, 3D ionospheric images can be constructed routinely. Lin et al. $(2007,2009)$ based on great amount of COSMIC RO soundings accumulated during 1 year have constructed global three-dimensional ionospheric maps to study the ionospheric seasonal effects. Liu et al. (2009) collected Ne profiles from COSMIC RO measurements to investigate the seasonal behaviors of daytime $\mathrm{Ne}$ at the altitude range of $200-560 \mathrm{~km}$. The most significant feature of this study is the presence of complicated global structures in the seasonal variations of $\mathrm{Ne}$ which has altitudinal dependency. This research is very important for global ionospheric studies, particularly in the context of space weather events.

In subsequent studies, we demonstrate the possible application of COSMIC RO measurements in studying ionosphere modification during geomagnetic disturbances. The ionosphere modification during the moderate geomagnetic disturbance which occurred on October 11, 2008 was analyzed in this study. A relatively weak but isolated geomagnetic disturbance is characterized by a well-pronounced positive effect observed in the European region during daytime. During October 11, 2008, the Dst (disturbance storm time) index reached $-60 \mathrm{nT}$ and the sum of the eight daily $\mathrm{Kp}$ values was 30+ (http://wdc.kugi.kyoto-u.ac.jp/wdc/Sec3.html). This disturbance occurred during a period of low solar activity.

The distinctive feature of this moderate geomagnetic storm was a rather short duration of the ionospheric effect observed over the European region. The strong short-term (about $2 \mathrm{~h}$ ) 

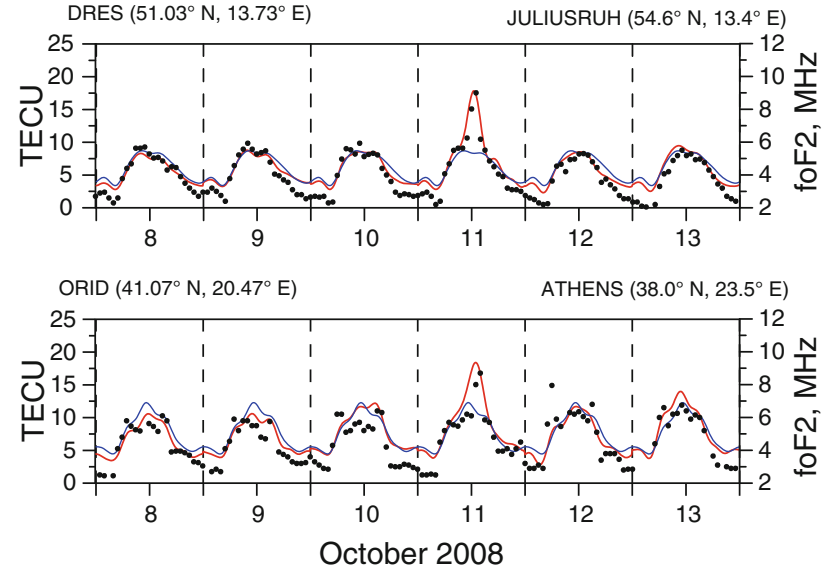

Fig. 12 Diurnal variations of TEC (red line) over DRES and ORID IGS GPS stations. The crosses indicate variations of foF2 over Juliusruh and Athens ionosondes. The blue line corresponds to the average TEC variation

positive effect reached a factor of 2 relative to undisturbed conditions. Figure 12 illustrates the diurnal variations of TEC (red line) over DRES and ORID GPS stations during October $8-13,2008$. In order to compare these results with quiet conditions, the blue line corresponds to the average TEC variations. A strong short-term TEC enhancement is clearly visible near noon on October 11 . The crosses indicate variations of foF 2 over Juliusruh and Athens ionosondes. The critical frequency variation also demonstrates the occurrence of a considerable positive effect.

Figure 13 illustrates the evaluation of COSMIC RO profiles registered during day-time at 9 UT, 13 UT and 16 UT for quiet and disturbed day. The geographic location of RO profiles corresponds to European mid-latitudes. A significant discrepancy between "quiet" and "disturbed" profiles is clearly seen at 13 UT. Peak electron density increased by a factor of 2.9 and the height of F2 layer maximum rose by $60 \mathrm{~km}$ in comparison with the quiet day profile. A com- parison of the profiles at $9 \mathrm{UT}$ and $16 \mathrm{UT}$ showed a rather good agreement in both the peak electron density values and the height of F2 layer maximum. This confirms the shortterm duration of the electron density enhancement over the European region during the considered disturbance.

Global mapping of the ionospheric electron density was carried out by using spherical harmonic expansion. Ne data corresponding to the various altitude ranges from 150-200 to $400-450 \mathrm{~km}$ with 2 -h resolution were selected. The distribution of $\mathrm{Ne}$ over the globe was represented with a spherical harmonic expansion up to a maximum degree and order values equal to 10, as shown in Eq. (2).

$$
\begin{aligned}
\operatorname{Ne}(\varphi, \lambda)= & \sum_{\substack{n=0 \\
m=0}}^{10} \sum_{n m}^{n} P_{n m}(\sin \varphi)\left(a_{n m} \cos (m \lambda)\right. \\
& \left.+b_{n m} \sin (m \lambda)\right)
\end{aligned}
$$

where $\varphi, \lambda$ are geographic latitude and longitude, $P_{n m}$ are the normalized associated Legendre functions; and $\mathrm{a}_{\mathrm{nm}}$ and $\mathrm{b}_{\mathrm{nm}}$ are the SH coefficients which were derived using COSMIC observations.

Figures 14 and 15 show the mean electron density maps for different altitude slices corresponding to 12 UT and 14 UT on October 9 and 11, 2008, respectively. At the bottom panel of these figures, respective global ionospheric VTEC maps provided by IGS are presented for the same time. One can clearly compare the ionosphere modification during the disturbed time versus a quiet day. A considerable enhancement of the spatial scale and magnitude of the equatorial ionization anomaly is observed within the African longitudinal sector at all slices. These graphs visualize the uplifting of the F2 layer near local noon on October 11. The most pronounced effect of the electron density increase occurred at the altitude range of $300-350 \mathrm{~km}$. It is also necessary to note that the considerable $\mathrm{Ne}$ increase effect at the altitudes of $350-400 \mathrm{~km}$ produced the modification of the topside part of the ionosphere.
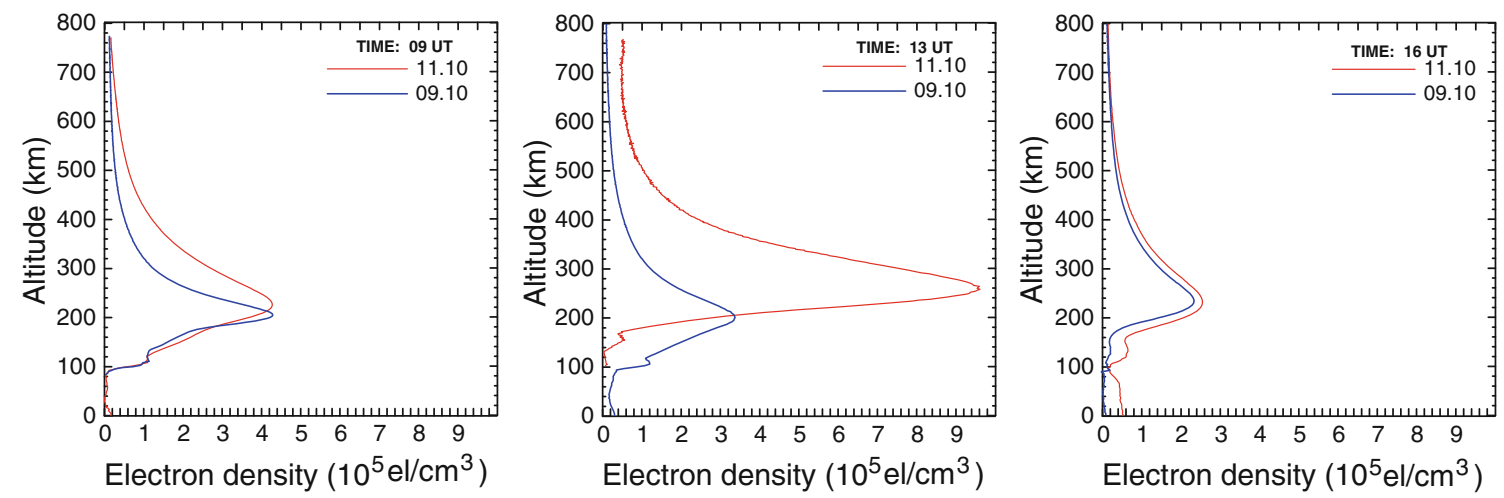

Fig. 13 Comparison of COSMIC electron density profiles at 9 UT, 13 UT and 16 UT on October 9 and 11, 2008 
Fig. 14 Global maps of the mean ionospheric electron density at various altitudes at 12 UT on October 9 (a) and 11 (b), 2008. The bottom panel presents the IGS TEC maps

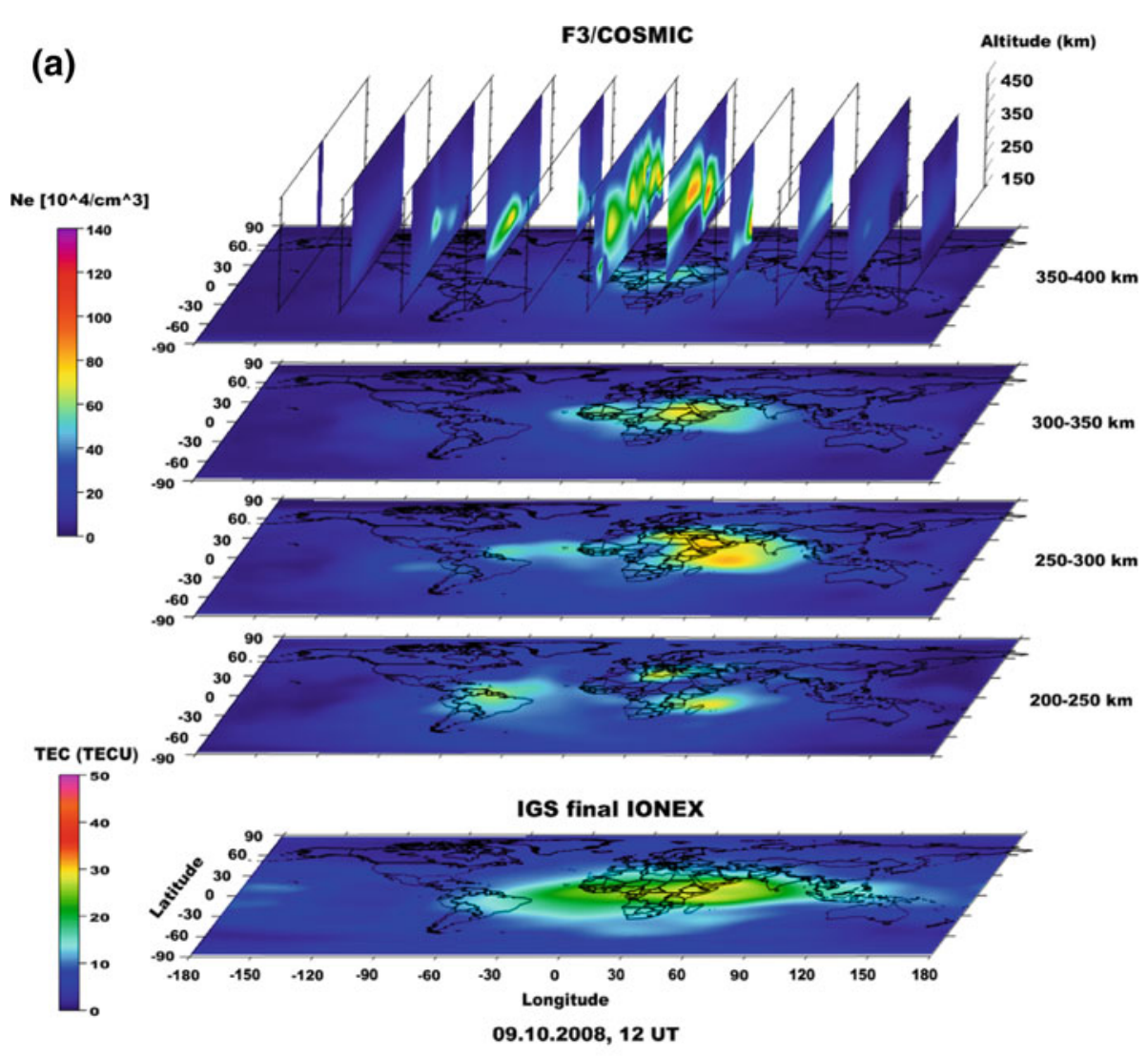

(b)

F3/Cosmic

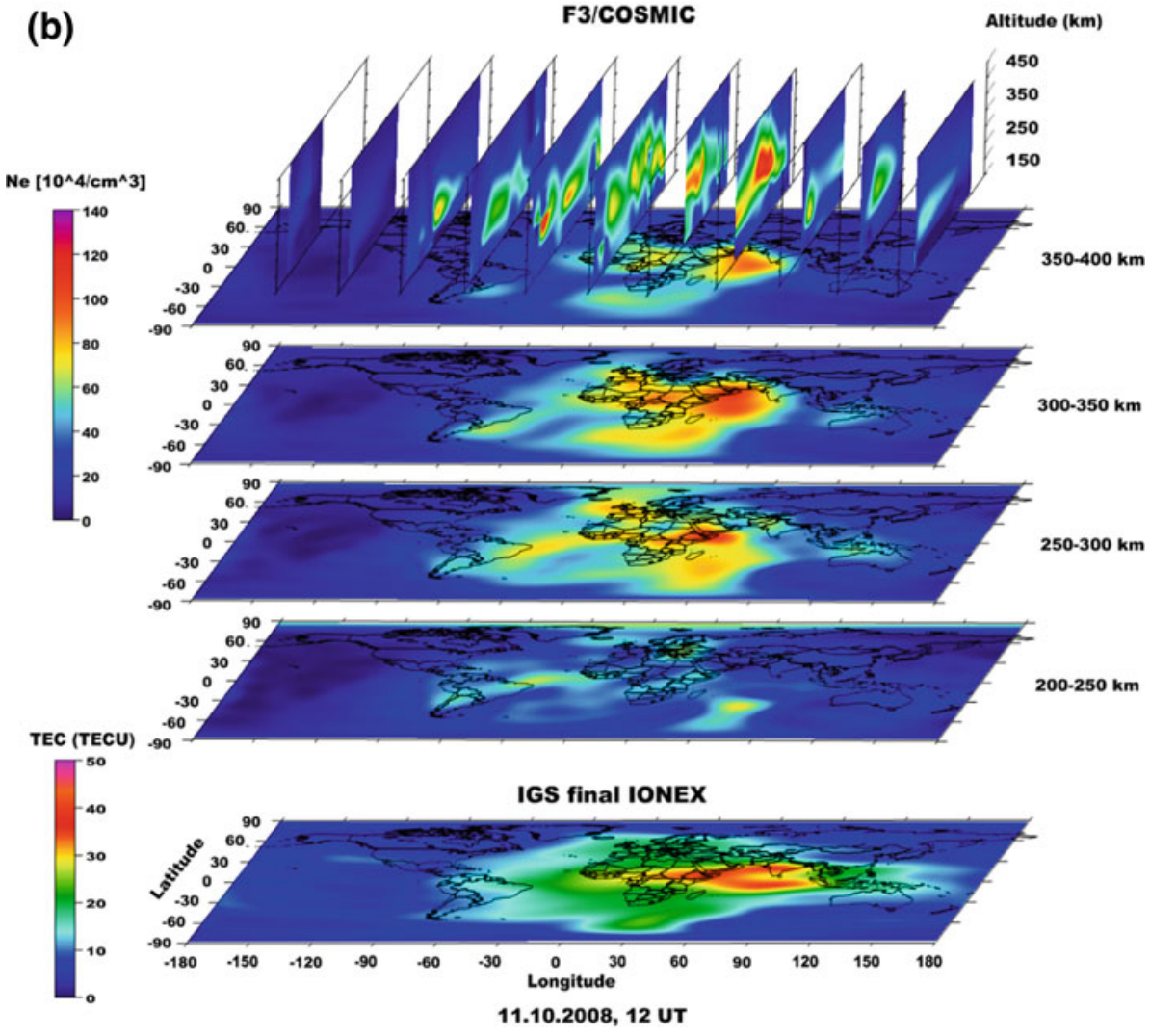

TEC (TEC
-40
-30
-20
-10
-0 
Fig. 15 Global maps of the mean ionospheric electron density at various altitudes at 14 UT on October 9 (a) and 11 (b), 2008. The bottom panel presents the IGS TEC maps

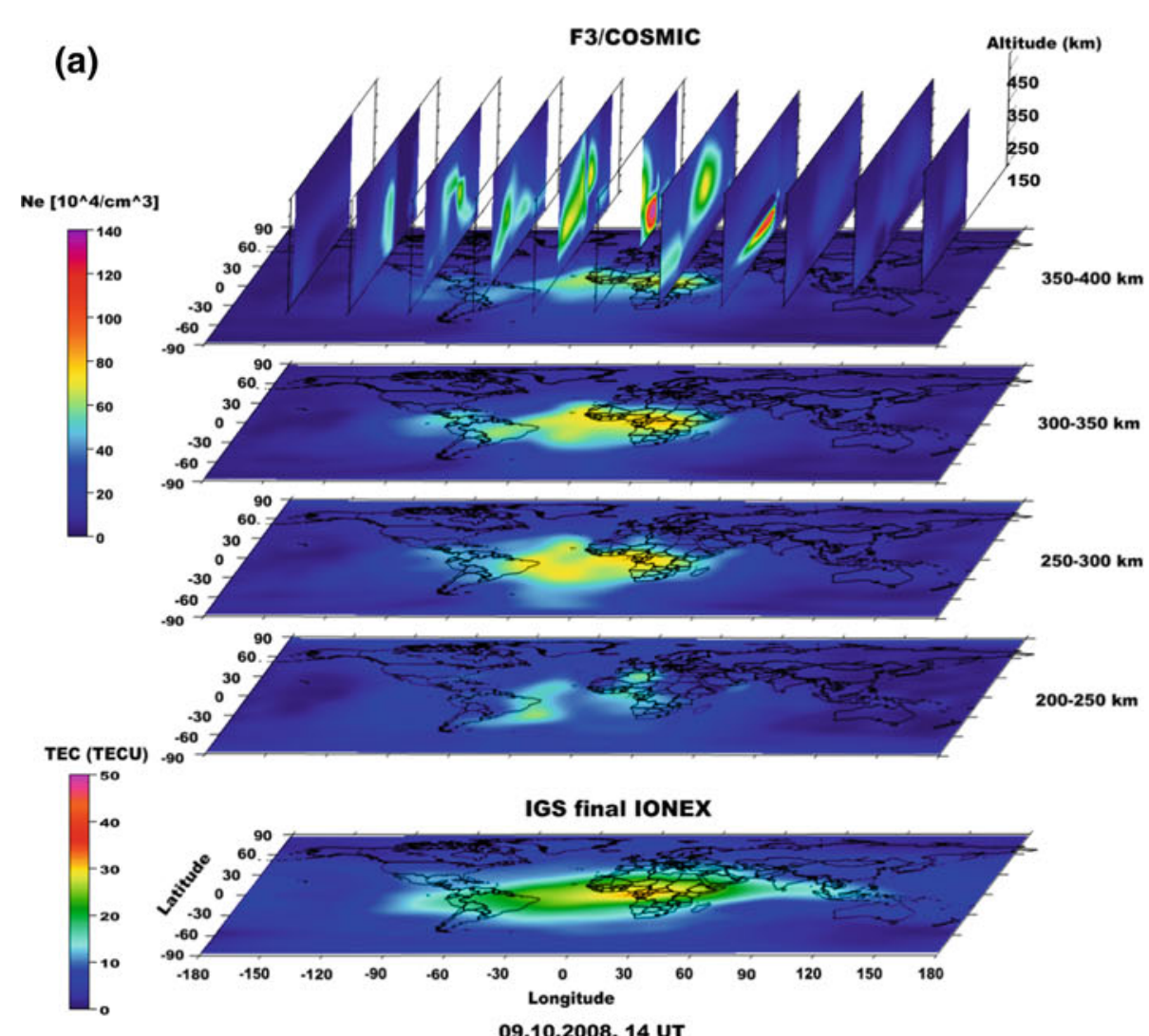

(b)

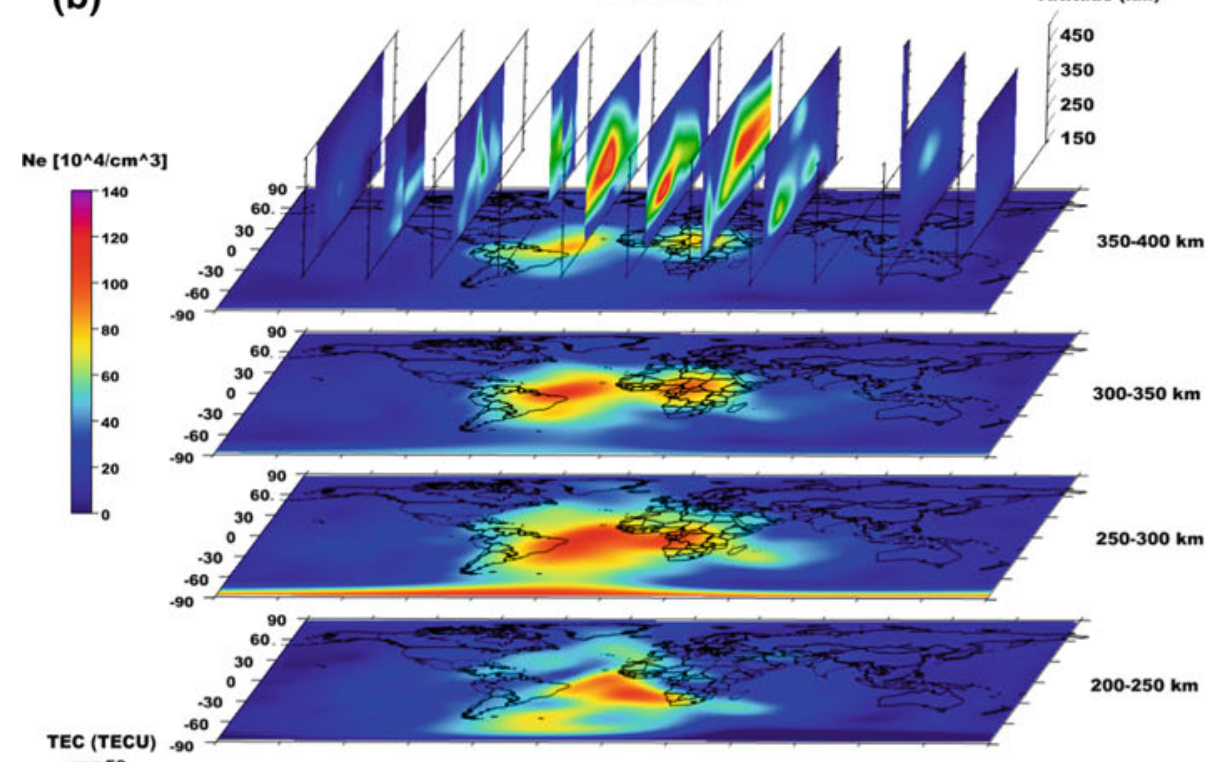

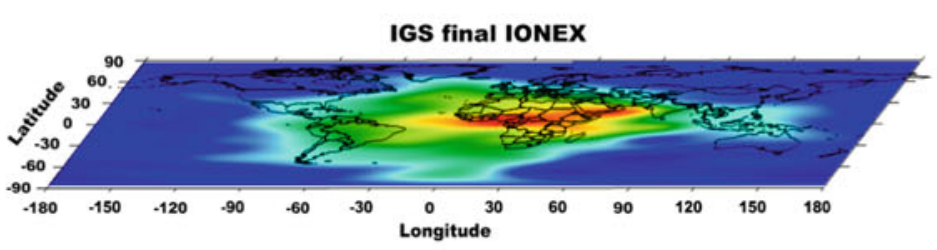

11.10.2008, 14 UT 


\section{Conclusion}

Analysis of COSMIC and ground-based data for the European region shows that COSMIC RO profiles are in generally good agreement with ionosonde profiles both in the $\mathrm{F} 2$ layer peak electron density $(\mathrm{NmF} 2)$ and the bottom side part of the profiles. This was confirmed by statistical analysis carried out for different seasons of 2008. COSMIC RO measurements have several advantages in comparison to traditional ground-based measurements-global distribution of the occultation events and probing of the topside part of the ionosphere, while the topside ionosonde profiles are obtained by fitting a model to the peak electron density values. COSMIC measurements can also be used to estimate the impact of the plasmasphere into the ionospheric TEC. In addition, RO techniques based on LEO constellation data gives very valuable information for the ionosphere diagnostics in the areas where ground-based stations do not exist. As COSMIC $\mathrm{RO}$ observations have a rather dense global distribution, they are potentially able to provide three-dimensional ionosphere images. This RO application provides an unprecedented possibility to study the vertical electron density distribution on a global scale that allows better understanding of the ionospheric structure and dynamics. Validation of the reliability of the COSMIC ionospheric observations is an enormous task that requires analysis and statistical generalization of a large amount of data. However, this technique already seems to be very promising for providing accurate profiles of the ionospheric electron density with high vertical resolution on a global scale.

Acknowledgments We wish to acknowledge the Taiwanese National Space Organization (NSPO) and the University Corporation for Atmospheric Research (UCAR) for providing the COSMIC Data. We are grateful to European Digital Upper Atmosphere Server (DIAS) for providing the ionosonde products and to the International GNSS Service (IGS) for GPS Data.

Open Access This article is distributed under the terms of the Creative Commons Attribution Noncommercial License which permits any noncommercial use, distribution, and reproduction in any medium, provided the original author(s) and source are credited.

\section{References}

Belehaki A, Cander LJ, Zolesi B, Bremer J, Juren C, Stanislawska I, Dialetis D, Hatzopoulos M (2005) DIAS Project: the establishment

of a European digital upper atmosphere server. J Atmos Solar-Terr Phys 67(12):1092-1099

Beyerle G, Schmidt T, Michalak G, Heise S, Wickert J, Reigber Ch (2005) GPS radio occultation with GRACE: atmospheric profiling utilizing the zero difference technique. Geophys Res Lett 32:L13806. doi:10.1029/2005GL023109
Colomb FR, Alonso C, Hofmann C, Nollmann I (2004) SAC-C mission, an example of international cooperation. Adv Space Res 34(10):2194-2199

Garcia-Fernandez M, Hernandez-Pajares M, Juan M, Sanz J (2003) Improvement of ionospheric electron density estimation with GPSMET occultations using Abel inversion and VTEC information. J Geophys Res 108:1338-1344. doi:10.1029/ 2003JA009952

Garcia-Fernandez M, Saito A, Juan JM, Tsuda T (2005) Threedimensional estimation of electron density over Japan using the GEONET GPS network combined with SAC-C data and ionosonde measurements. J Geophys Res 110:A11304. doi:10.1029/ 2005JA011037

Hajj GA, Romans LJ (1998) Ionospheric electron density profiles obtained with the global positioning system: results from the GPS/MET experiment. Radio Sci 33:175-190. doi:10.1029/ 97RS03183

Hernandez-Pajares M, Juan JM, Sanz J (2000) Improving the Abel in version by adding ground GPS data to LEO radio occultations in the ionospheric sounding. Geophys Res Lett 27:2743-2746. doi:10.1029/2000GL000032

Hocke K, Igarashi K (2002) Structure of the Earth's lower ionosphere observed by GPS/MET radio occultation. J Geophys Res 107:A5. doi:10.1029/2001JA900158

Jakowski N (2005) Ionospheric GPS Radio Occultation measurements on board CHAMP. GPS Solut 9:88-95. doi:10.1007/ s10291-005-0137-7

Jakowski N, Wehrenpfennig A, Heise S, Reigber C, Lühr H, Grunwaldt L, Meehan TK (2002) GPS radio occultation measurements of the ionosphere from CHAMP: early results. Geophys Res Lett 29(10):1457. doi:10.1029/2001GL014364

Kirchengast G, Foelsche U, Steiner A (eds) (2004) Occultations for probing atmosphere and climate. ISBN:978-3-540-22350-4

Klobuchar JA, Kunches JM (2000) Eye on the ionosphere: the spatial variability of ionospheric range delay. GPS Solut 3(3):70-74. doi:10.1007/PL00012808

Kuo Y-H, Wee T-K, Sokolovskij S, Rocken C, Schreiner W, Hunt D, Anthes RA (2004) Inversion and error estimation of GPS radio occultation data. J Meteorol Soc Jpn 82(1B):507-531

Lei J, Syndergaard S, Burns AG, Solomon SC, Wang W, Zeng Z, Roble RG, Wu Q, Kuo Y-H, Holt JM, Zhang S-R, Hysell DL, Rodrigues FS, Lin CH (2007) Comparison of COSMIC ionospheric measurements with ground-based observations and model predictions: preliminary results. J Geophys Res 112:A7. doi:10. 1029/2006JA012240

Lin CH, Liu JY, Fang TW, Chang PY, Tsai HF, Chen $\mathrm{CH}$, Hsiao CC (2007) Motions of the equatorial ionization anomaly crests imaged by FORMOSAT-3/COSMIC. Geophys Res Lett 34:L19101. doi:10.1029/2007GL030741

Lin CH, Liu JY, Hsiao CC, Liu CH, Cheng CZ, Chang PY, Tsai HF, Fang TW, Chen CH, Hsu ML (2009) Global ionospheric structure imaged by FORMOSAT-3/COSMIC: early results. Terr Atmos Ocean Sci 20:171-179. doi:10.3319/TAO.2008.01.18.01(F3C)

Liou YA, Pavelyev AG, Matyugov SS, Yakovlev OI, Wickert J (2010) Radio occultation method for remote sensing of the atmosphere and ionosphere. InTech. ISBN:978-953-7619-60-2

Liu L, Zhao B, Wan W, Ning B, Zhang M-L, He M (2009) Seasonal variations of the ionospheric electron densities retrieved from constellation observing system for meteorology, ionosphere, and climate mission radio occultation measurements. J Geophys Res 114:A2. doi:10.1029/2008JA013819

McNamara LF (2006) Quality figures and error bars for autoscaled Digisonde vertical incidence ionograms. Radio Sci 41:RS4011. doi:10. 1029/2005RS003440 
Reinisch BW, Huang X (2001) Deducing topside profiles and total electron content from bottomside ionograms. Adv Space Res 27(1):23-30

Reinisch BW, Huang X, Galkin IA, Paznukhov V, Kozlov A (2005) Recent advances in real-time analysis of ionograms and ionospheric drift measurements with digisondes. J Atmos SolarTerr Phys 67:1054-1062

Schreiner WS, Sokolovskiy SV, Rocken C, Hunt DC (1999) Analysis and validation of GPS/MET radio occultation data in the ionosphere. Radio Sci 34:949-966. doi:10.1029/1999RS900034

Straus PR, Anderson PC, Danaher JE (2003) GPS occultation sensor observations of ionospheric scintillation. Geophys Res Lett 30(8):1436. doi:10.1029/2002GL016503

Syndergaard S, Schreiner WS, Rocken C, Hunt DC, Dymond KF (2006) Preparing for COSMIC: inversion and analysis of ionospheric data products. In: Foelsche U, Kirchengast G, Steiner AK (eds) Atmosphere and climate: studies by occultation methods. Springer, New York, pp 137-146

Tsai LC, Tsai WH, Schreiner WS, Berkey FT, Liu JY (2001) Comparisons of GPS/MET retrieved ionospheric electron density and ground based ionosonde data. Earth Planets Space 53:193-205
Tsai LC, Liu CH, Hsiao TY (2009) Profiling of ionospheric electron density based on FormoSat-3/COSMIC data: results from the intense observation period. Terr Atmos Ocean Sci 20:181-191. doi:10.3319/TAO.2007.12.19.01(F3C)

Wickert J, Michalak G, Schmidt T, Beyerle G, Cheng C-Z, Healy SB, Heise S, Huang C-Y, Jakowski N, Kohler W, Mayer C, Offiler D, Ozawa E, Pavelyev AG, Rothacher M, Tapley B, Arras C (2009) GPS radio occultation: results from CHAMP. GRACE and FORMOSAT-3/COSMIC. Terr Atmos Ocean Sci 20(1):3550

Wu X, Hu X, Gong X, Zhang X, Wang X (2009) Analysis of inversion errors of ionospheric radio occultation. GPS Solut 13(N3):231239. doi:10.1007/s10291-008-0116-x

Yue X, Wan W, Liu L, Mao T (2007) Statistical analysis on spatial correlation of ionospheric day-to-day variability by using GPS and incoherent scatter radar observations. Ann Geophys 25:1815-1825

Yue X, Schreiner WS, Lei J, Sokolovskiy SV, Rocken C, Hunt DC, Kuo Y-H (2010) Error analysis of Abel retrieved electron density profiles from radio occultation measurements. Ann Geophys 28: $217-222$ 